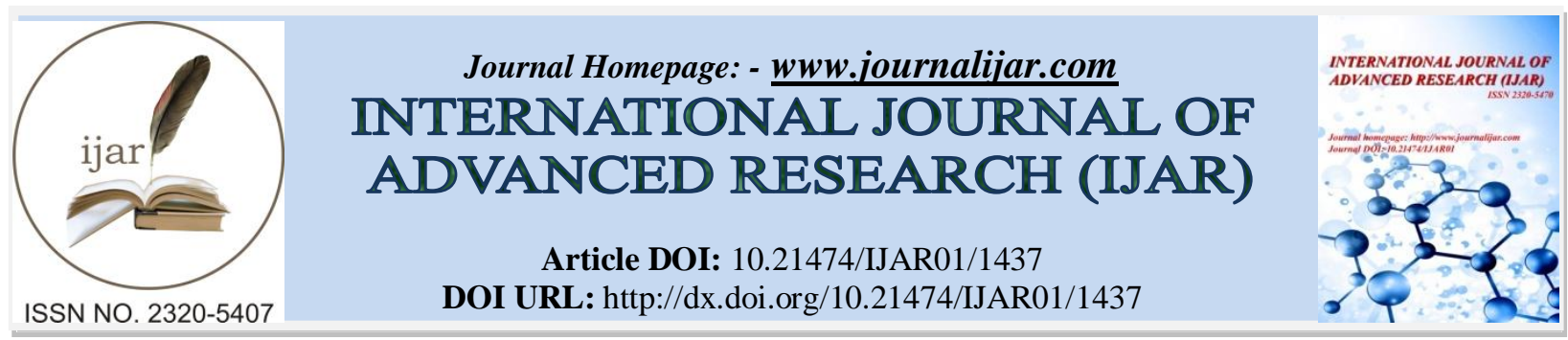

RESEARCH ARTICLE

\title{
UPDATING IN DIAGNOSIS OF BLOOD STREAM INFECTION IN IMMUNOCOMPROMISED PATIENTS WITH HAEMATOLOGICAL MALIGNANCIES.
}

Nagwa M Shawky ${ }^{1}$, Nahla I El Attar ${ }^{1}$, Fouad M Abu Taleb ${ }^{2}$ and Hytham K Ahmed ${ }^{1}$.

1. Department of Clinical pathology, Faculty of Medicine, Zagazig University, Zagazig, Egypt.

2. Department of Haematology-Oncology, Faculty of Medicine, Zagazig University, Zagazig, Egypt.

\section{Manuscript Info}

Manuscript History

Received: 15 June 2016

Final Accepted: 16 July 2016

Published: August 2016

Key words:-

blood stream infection; blood cultures ;broad range PCR;Genus specific multiplex PCR ; Candida specific PCR.

\section{Abstract}

Introduction: Diagnosis of bloodstream infections using microbiological cultures suffers from low sensitivity and reporting delay. Advanced molecular techniques introduced in many laboratories provide rapid results and may show improvements in patient outcomes. This study aimed to evaluate the usefulness of a molecular technique, broad-range 16S rRNA PCR followed by Genusspecific multiplex PCR and Candida specific nested PCR for the diagnosis of bloodstream infections in immunocompromised patients with haematological malignancies, compared to automated blood culture .Methodology: Conventional broad-range PCR and candida specific nested PCR were performed, on EDTA blood and plasma samples collected from different patients with haematological malignancies complaining of febrile neutropenia; Positive cases by broad range PCR identified by genus specific multiplex PCR. results were compared with those of automated blood culture. Results: Though blood culture is regarded as the gold standard, Broad range PCR evaluation showed Sensitivity of $83.3 \%$,specificity of $86.8 \%$, Positive predictive value of $66.7 \%$, Negative predictive value of 94.3\% and accuracy of $86.0 \%$.Candida specific nested PCR evaluation showed Sensitivity of $100 \%$,specificity of $89.6 \%$, Positive predictive value of $28.6 \%$, Negative predictive value of $100 \%$ and accuracy of $90 \%$. and the results of both techniques correlated well with those of blood culture. Conclusions: Molecular assays are promising method that can be used in the rapid diagnosis of bloodstream infections but they seem not to be sufficient to replace microbial cultures which must associate these techniques.

\section{Introduction:-}

Bacterial bloodstream infections (BSIs) rank first in terms of infectious complications during neutropenia and the inadequacy of the inflammatory response makes sepsis a significant cause of death in this setting. Therefore, febrile neutropenia should be considered a medical emergency and a prompt administration of empirical antibiotic therapy is mandatory, since it has been associated with lower morbidity and mortality (Gustinetti and Mikulska ,2016). Candidemia is still a genuine infection in hematology patients, in spite of the fact that the occurrence of candidemia 
has diminished with the presentation of azole medications in the 1990 (Nogaard ,2012). Blood cultures are considered the gold standard in the diagnosis of bloodstream infections (BSIs) (Rodriguez-Creixems et al., 2008) Blood cultures have shown low sensitivity in the detection of bacterial agents in cases of low-grade bacteraemia, in cases where adequate sample volume for inoculation in blood culture bottles cannot be obtained, and in cases where antibiotics are used before blood sampling (Isaacman et al.,1996). New developments in the diagnosis of BSIs include the use of new blood biomarkers (Pierrakos and Vincent, 2010), revised clinical criteria, and new molecular pathogen detection methods (Murray and Masur ,2012). Molecular pathogen detection methods are based on two main principles - hybridization or amplification. Hybridization-based methods such as fluorescence in situ hybridization (FISH) can be applied to positive blood cultures using oligonucleotide probes that target consensus bacterial genes (typically rRNA genes) (Kempf et al.,2000). Amplification methods (e.g., polymerase chain reaction [PCR] have been used to amplify specific target regions in the microbial genome. For amplification based techniques it include broad range assays, Pathogen specific assays and multiplex PCR assays(Mancini et al.,2010)..For broad range assays further Identification of microorganisms can be performed by PCR algorithms, taxon-specific oligonucleotide microarray, or sequencing amplification(Arabestani et al.,2014).Broad-range PCR targets the 16S rRNA gene, a consensus gene that is present in all bacteria and consists of two regions - conserved and variable. The conserved regions are targeted by universal primers for detection of the presence of a microorganism; the variable regions are targeted by genus or species-specific primers (Woese,1987).

This study aimed to evaluate the usefulness of a molecular technique, broad-range 16S rRNA PCR followed by Genus-specific multiplex PCR and Candida specific nested PCR for the diagnosis of bloodstream infections in immunocompromised patients with haematological malignancies, compared to automated blood culture

\section{Subjects and Methods:-}

This work was carried out at the Departments of Clinical Pathology, oncology and haematology, Zagazig University Hospitals from February 2013 to October 2013.

\section{Subjects:-}

Selection of patients and controls:-

It included 50 immunocompromised patients with different types of haematological malignancies referred from haematology and Oncology Department, Zagazig University Hospitals and had episodes of fever and neutropenia during the period of study. They included 30 AML patients(G1 subgroup), 14 ALL patients(G2 subgroup) and 6 NHL patients(G3 subgroup) together with 20 controls age and sex matched with absence of any clinical signs and symptoms of infection.

\section{Definition of episode of fever and neutropenia:-}

An episode of fever and neutropenia was defined as two consecutive readings of oral temperature $38.0^{\circ} \mathrm{C}$ or more within 2 hours and an absolute neutrophil count $<500 / \mu 1$, or $(500-1000 / \mu 1)$ and expected to fall below $500 / \mu 1$ in the next 48 hours).all febrile neutropenic patients managed according to ESMO guidelines for treatment of febrile neutropenia. (De Naurois et al.,2010)

\section{Blood samples:-}

Thirteen milliliters $(13 \mathrm{ml})$ of venous blood were collected from all subjects at the start of onset of fever and taken under complete aseptic conditions then divided into: $10 \mathrm{ml}$ of blood for automated blood culture, $3 \mathrm{ml}$ EDTA-blood for $\mathrm{CBC}$ and molecular techniques.

\section{Methods:-}

Automated Blood culture:-

Blood culture vials were inoculated in an automated continuous- monitoring blood culture system, Bact/Alert 60 (Biomerieux ,Marcy-l'Etoile ,France).The bottles were incubated immediately upon receipt in the microbiology laboratory in accordance with the manufacture's recommendation. Blood culture vials were supplied and stored according to the manufacturer's instructions. Blood samples were collected using sterile techniques to reduce contamination. Subculture was done from positive culture vials on blood, MacConkey and sabroud`s dextrose agar media. The culture bottles that did not show any sign of bacterial growth after seven days of incubation were reported as negative. Further identification to identify the species done by vitek MS system. 


\section{Molecular techniques for diagnosis of bacterial blood stream infection:-}

Bacterial DNA was extracted from $500 \mu$ whole blood sample, using the method previously described by jordan and durso (2005).PCR controls were prepared from reference strains (E. coli ATCC 8739), (Staph Aureus ATCC 29213), (Pseudomonas airuginosa ATCC 27853) and (Enterococcus fecalis ATCC 29212) ) provided from (Biomerieux, Marcy-l'Etoile,France) . Genomic bacterial DNA extraction from culture plate was done as described by Arabestani et al.,2014 using the QIAamp DNA Mini Kit (Qiagen, Hilden, Germany)

\section{Universal broad range bacterial PCR:-}

Eubacterial broad-range 16S rRNA primer set (Biosearch technologies . Petaluma, CA, U.S.A) was used to amplify approximately $1.500 \mathrm{bp}$ of a consensus $16 \mathrm{~S} r D N A$ gene. Universal primers were: $5^{\prime}$-AGA GTT TGA TCA TGG CTC AG-3' as forward (located at positions 8-27).

5'-GGT TAC CTT GTT ACG ACT T-3' as reverse (located at positions 1509-1491) [5]. Briefly, TopTaq Master Mix,2x(Qiagen, Hilden, Germany) was mixed by vortexing briefly and $25 \mu 1$ was dispensed into each PCR tube with final concentration ( $1.25 \mathrm{U}$ top taq DNA polymerase/reaction, 1x PCR buffer with $1.5 \mathrm{mM} \mathrm{MgCl} 2,200 \mathrm{mM}$ of each deoxynucleotide triphosphate (dNTPs) , $1 \mu$ of each forward and reverse working primer solution with 10 $\mathrm{pmol} / \mu \mathrm{l}(10 \mu \mathrm{M})$ was added with final concentration of $0.2 \mu \mathrm{M}, 4 \mu \mathrm{l}$ of template DNA was added, $19 \mu \mathrm{l}$ of RNase free water was added to reach final volume $50 \mu 1$, Positive and negative controls were performed in in each assay to determine false results. DNA from Escherichia coli (E. coli ATCC 8739 ) was used as positive control, and sterile water and PCR mixtures (without template) as negative controls. The PCR reaction tubes were placed in the thermal cycler and start the cycling program as follows:

An initial preincubation at $94{ }^{\circ} \mathrm{C}$ for 3 minutes, then was followed by 35 cycles of 30 seconds denaturation at $94{ }^{\circ} \mathrm{C}$, 30 seconds annealing at $60^{\circ} \mathrm{C}$ and 60 seconds extension at $72^{\circ} \mathrm{C}$. There were final extension period at $72^{\circ} \mathrm{C}$ for 10 minutes after completion of the cycling sequence.

\section{Genus specific multiplex PCR:-}

Primers were targeted at the characteristic 16s rRNA (variable regions) for the following genera Enterococcus ,Staphylococcus and Pseudomonas and for 23s rRNA gene for enterobacteriacea (Mitsuda et al.,2011). primers used were Enterobacteriaceae 23S rRNA

\section{En-lsu3 F TGCCGTAACTTCGGGAGAAGGC \\ En-lsu3 R TCAAGGCTCAATGTTCAGTGTC \\ Enterococcus 16S rRNA: \\ Ec-ssu1 F GGATAACACTTGGAAACAGG \\ Ec-ssu1 R TCCTTGTTCTTCTCTAACAA \\ Staphylococcus 16S rRNA: \\ STPY F ACGGTCTTGCTGTCACTTATA \\ STPY R TACACATATGTTCTTCCCTAATAA \\ Pseudomonas 16S rRNA: \\ PSD7 F CAAAACTACTGAGCTAGAGTACG \\ PSD7 R TAAGATCTCAAGGATCCCAACGGCT}

The method of DNA amplification was carried out using Qiagen multiplex plus kit (Qiagen, Hilden,Germany) as described by the manufacture. Briefly ,25 $\mu 12 x$ Multiplex PCR Master Mix was mixed with $5 \mu 1$ from(10xprimer mix, $2 \mu \mathrm{M}$ each primer), Q-solution, CoralLoad Dye and RNase-free water to prepare reaction mix to which $5 \mu 1$ template DNA was added followed by adequate mixing, Positive and negative controls were performed in each assay to determine false results.DNA from Reference strains (E. coli ATCC 8739),(Staph Aureus ATCC 29213),(Pseudomonas airuginosa ATCC 27853) and (Enterococcus fecalis ATCC 29212) was added as positive control, and sterile water and PCR mixtures (without template) were used as negative controls.PCR reaction tubes were placed in the thermal cycler and start the cycling program as follow :An initial preincubation at $95 \mathrm{C}$ for 5 minutes, then was followed by 35 cycles of 30 seconds denaturation at $95^{\circ} \mathrm{C}, 90$ seconds annealing at $60^{\circ} \mathrm{C}$ and 30 seconds extension at $72^{\circ} \mathrm{C}$. There were final extension period at $68^{\circ} \mathrm{C}$ for 10 minutes after completion of the cycling sequence.Samples were analyzed on agarose gel $3 \%$ by gel electrophoresis. Results were interpretated as follow The negative control was examined to exclude any source of contamination. The positive control was examined for the 
presence of sharp bands at $428 \mathrm{bp}$ for Enterobacteriaceae, $257 \mathrm{bp}$ for staphylococcus spp. , $215 \mathrm{bp}$ for pseudomonas spp. And 115 bp for Enterococcus spp.

\section{Molecular techniques for diagnosis of candida blood stream infection:-}

Nested PCR using two sets of primers was used to increase the sensitivity and specificity of the assay. Total DNA from $200 \mu \mathrm{l}$ plasma was extracted using QIAamp DNA Mini Kit supplied by QIAGEN companies. plasma sample was preferred due to higher sensitivity than whole blood for detection of candida DNA( Lau et al.,2009; Nguyen et al.,2012). PCR controls for candida prepared from isolated Candida albicans strain grown on sabroud dextrose agar for 48 hours. Genomic Candida DNA extraction was done as described by Metwally et al., (2007) using the QIAamp DNA Mini Kit (Qiagen, Hilden, Germany).

$2 \mu 1$ of extracted DNA mixed with $1 \mu 1$ of each forward and reverse working panfungal primer solution with 10 $\mathrm{pmol} / \mu \mathrm{l}$ were subjected to the first round of amplification using ready to go PCR beads Maxime PCR PreMix Kit . (i-Taq; for $20 \mu \mathrm{l}$ reaction, Intron Biotechnology, Inc.) which contain all the reagents necessary for PCR reaction except primers and template. $16 \mu \mathrm{l}$ of distilled water was added to reach final volume $20 \mu \mathrm{l}$,Positive and negative controls were performed in in each assay to determine false results. For first round of amplification the Panfungal primers were used. (Jaeger et al.,2000)

Pffor : $5 `$ AGGGATGTATTTATTAGATAAAAAATCAA 3`. Pfrev2 : 5 CGCAGTAGTTAGTCTTCAGTAAATC 3'.

All tubes were transferred to the thermal cycler (Gene Amp PCR system, Applied Biosystems, USA) where they were subjected to initial one cycle of denaturation at $95 \mathrm{C}^{\circ}$ for $5 \mathrm{~min}$ followed by 40 cycles of denaturation at $95 \mathrm{C}^{\circ}$ for $30 \mathrm{sec}$, annealing at $58 \mathrm{C}^{\circ}$ for $30 \mathrm{sec}$ and extension at $72 \mathrm{C}^{\circ}$ for $20 \mathrm{sec}$, and final one cycle of extension at $72 \mathrm{C}^{\circ}$ for $7 \mathrm{~min}$. Three ul of the amplified panfungal products were used to carry a 2nd amplification (Nested PCR) using the Candida primers by the same method of amplification with the exception of annealing temperature, which was $66 \mathrm{C}^{\circ}$ using the following primers :Candida species primers (Jaeger et al.,2000)

CaFor 2 : 5' GGGAGGTAGTGACAATAAATAAC 3'. Carev3 : 5'CGTCCCTATTAATCATTACGAT 3'.

The final PCR products were visualized with UV transilluminator after electrophoresis on $2 \%$ agarose gels, stained with ethidium bromide. The positive control was examined for the presence of sharp bands at 402 bp Samples were compared with controls (Jaeger et al.,2000).

\section{Statistical methods:-}

Statistical analysis was performed using SPSS statistical software version 15 (SPSS Inc., Chicago, IL, USA). Agreement between different diagnostic techniques was tested using kappa statistic. A p value of $<0.05$ was considered statistically significant.

\section{Results:-}

The results of the study showed that for patients group a total of 50 samples from immunocompromised patients with haematological malignancies suspected for having bactereamia (Febrile neutropenic patients) were taken for automated continuously monitoring blood culture (Bact-Alert/60 system), 14 samples were found to be positive. As regard AML cases (G1 subgroup), 8 cases showed bacterial growth and 2 cases showed growth as candida. As regard ALL cases (G2 subgroup), 3 cases showed bacterial growth .As regard NHL cases (G3 subgroup), 1 case showed bacterial growth .There was non significant difference between different types of haematological malignancies and occurrence of bacterial or candida infection diagnosed by Bact-Alert system. Control group didn`t show any positive samples by bact-Alert system. Further identification is done by Vitek MS system that reveals that 12 samples showed bacterial growth (6 gram positive isolates and 6 gram negative isolates) and 2 samples showing growth for candida. Samples showing bacterial growth ( 2 Staphylococcus hominis, 1 Staphylococcus epidermidis, 2 Staphylococcus aureus, 1 Enterococcus fecalis , 2 Klebsiella pneumonia, 1 E. coli, 1 Serratia marcescens, 1 Enterobacter cloaca , 1 Pseudomonas aeruginosa) while samples showing growth for candida ( 1 Candida albicans , 1 Candida tropicalis). The universal broad range bacterial PCR was performed, for patients group, 15 samples were found to be positive. As regard AML cases (G1 subgroup), 10 cases found to be positive. As regard ALL cases (G2 subgroup), 4 cases found to be positive. As regard NHL cases (G3 subgroup), 1 case found to be positive. There 
was non significant difference between different types of haematological malignancies and occurrence of bacterial infection diagnosed by universal broad range bacterial PCR . For Control group, No positive samples were detected .To identify bacterial isolate, Genus-Specific multiplex PCR was performed on these 15 isolates, Specific multiplex PCR was planned for identification of four common genera of bacteria famous for blood stream infection (Staph spp., Enterococcus spp., Enterobacteriacea and Pseudomonas spp.) All of the 15 isolates showed amplification by specific multiplex PCR (8 Enterobacteriacea, 3 Staphylococcus species, 3 Pseudomonas species and 1 Enterococcus species). Of the 12 BC-positive patients for bacteria, 10 were also universal broad range PCR positive and specific multiplex PCR positive with complete matching between identification done by specific multiplex PCR and Vitek MS following automated blood culture. The two samples that were positive by BC but negative by PCR were Staphylococcus hominis and Staphylococcus aureus, moreover, the five samples that were positive by PCR but negative by BC included two PCR positive with pseudomonas spp. and three with Enterobacteriaceae. There was a high degree of concordance between automated blood culture and universal broad range 16s PCR technique which was $86 \%$ in both positive and negative results.

Candida specific nested PCR was performed, For patients group, 7 samples were found to be positive. The two samples that were positive by automated blood culture were also positive by Candida specific nested PCR, Moreover 5 new samples were positive by PCR and negative by blood culture. as regard AML patients (G1 subgroup) 6 cases found to be positive. as regard ALL patients (G2 subgroup) 1 case found to be positive. as regard NHL patients (G3 subgroup) no proved positive case. There was non significant difference between different types of haematological malignancies and occurrence of candida infection diagnosed by Candida specific nested PCR. For Control group, No positive samples were detected. There was high degree of concordance between automated blood culture and candida specific PCR technique which was $90 \%$ in both positive and negative results.

Evaluation of the molecular techniques:-

For (universal broad range PCR followed by genus- specific multiplex PCR) Sensitivity, specificity, predictive values of positive and negative and accuracy are measured compared to blood culture (The gold standard for diagnosis of blood stream infection). Sensitivty of $83.3 \%$,specificity of $86.8 \%$, Positive predictive value of $66.7 \%$ , Negative predictive value of $94.3 \%$ and accuracy of $86.0 \%$.Correlation with the gold standard (Blood culture) shows high degree of agreement between the two methods (Kappa agreement $0.64 \pm 0.13 p<0.001)$ (Table 1).

For Candida specific nested PCR Detection of sensitivity ,specificity, negative and positive predictive values and accuracy compared with the gold standard technique (Blood culture) Sensitivity of $100 \%$,specificity of $89.6 \%$, Positive predictive value of $28.6 \%$, Negative predictive value of $100 \%$ and accuracy of $90 \%$. It was found that sensitivity and negative predictive values was excellent $100 \%$ in both of them. This makes the test as good negative and can be used to roll out of infections. Correlation with the gold standard (Blood culture) shows high degree of agreement between the two methods (Kappa agreement $0.407 \pm 0.11, p$ value $<0.001$ ). (Table 2).

The turnaround times of blood cultures versus PCR were compared. Molecular techniques show shorter turnaround time than automated blood culture which is critical especially for cases with febrile neutropenia but they lack reports for antimicrobial sensitivity (Table 3).

\section{Discussion:-}

Management of febrile neutropenia in hematological patients undergoing intensive chemotherapy is important, because bacterial or fungal infections during prolonged neutropenia are major causes of morbidity and mortality in these patients, Those infections can rapidly become life-threatening if not treated appropriately and promptly(Phillips et al.,2016). The time window for the administration of an appropriate therapy is less than 6 hours once the symptoms are recognized. Inadequate antimicrobial therapy increases the risk of mortality, Every hour of delay in initiation of appropriate antimicrobial therapy increases the mortality by $7.6 \%$ in patients with septic shock. (Jordana-Lluch et al., 2014).

The current gold standard for the detection of microbial pathogens in blood is blood culture(Kirn and Weinstein, 2013).Yet, the diagnosis of bloodstream infection (BSIs) in neutropenic patients remains challenging, because all blood culture systems suffer from several limitations, such as lack of rapidity and low sensitivity, especially when the patient has already received antibiotics and when fastidious micro-organisms are involved(Dark et al., 2009). This conventional laboratory method has a low pre-test probability in certain clinical settings, and is impaired by the delay in the time to result, In order to increase the speed of diagnosis, to improve sensitivity and the clinical benefit 
of detection of pathogens in the blood, new methods have been developed. Molecular techniques for detection of bacterial and fungal DNA have been implemented aiming for shortening the time to pathogen identification and allowing for detection of organisms missed by blood culture, molecular methods may contribute to the reduction of hospitalization and ICU stay, as well as decreases in mortality(Liesenfeld et al.,2014)

In the present study, Of 50 samples taken from patients with febrile neutropenia pathogenic bacterium was detected in the blood culture of $24 \%$ of the cases which is in the positivity range of many other different studies done on haematological malignancy patients complaining of febrile neutropenia (Lamoth et 2010 ; Gedik et al.,2014). On the other hand other studies shows higher positivity rate (Von Lilienfeld-Toal et al.,2009;Lakshmaih et al.,2015) and others show lower positivity rates(Teranishi and Ouchi, 2014). These differences in positivity of blood culture result may be attributed to differences in blood volume withdrawn, blood culture techniques and exposure to antimicrobials(Draz et al.,2013). with universal broad range PCR, the detection of bacteria was 30\% This improvement in bacterial detection by using PCR goes in accordance with different studies( Wellinghousen et al. 2009; Teranishi and ouchi 2014; Arabestani et al. 2014).

Five patients tested positive for PCR but had negative blood cultures. These may be interpretated by detection of non viable organism(Rothman et al.,2002) or PCR reagents contamination with microbial DNA (Muhl et al.,2010).

In 2 of 12 BC-positive patients, the PCR results were negative. This may have been caused by common technical factor - difficulties in breaking the cell walls of Gram-positive organisms during sample preparation - which resulted in the failure of the DNA extraction process (Rothman et al.,2002). Presence of two cases diagnosed only by culture and missed by the molecular technique makes the interpretation of results of these techniques should be done cautiously and hand-in-hand with blood culture which must associates these techniques and can't be replaced by them.

For evaluation of universal broad range PCR and genus-specific multiplex PCR assays against blood culture, regarded as the gold standard, showed a sensitivity of $83.3 \%$, specificity of $86.8 \%$, positive predictive value of $66.7 \%$, negative predictive value of $94.3 \%$, and accuracy of $86.0 \%$ respectively moreover the results obtained by the molecular technique correlated well with those obtained by blood culture(Kappa coeffient $0.64 \pm 0.13 \mathrm{p}<0.001$ ). These values are similar to those found in other studies using conventional or automated PCR techniques (arabestani et al.,2014; wellinghousen et al.,2009) which their results correlated well with the gold standard (Blood culture).

In the current study, Automated blood culture for Candida were positive in only 2 samples out of the 50 tested samples for febrile neutropenic patients with haematological malignancies (4\%). While by using PCR technique, Candida spp. were detected in 7 samples (14\%). Similar findings were reported by (Badiee et al., 2009) as out of 194 patients with hematological malignancies, 25 were PCR positive for Candida spp. (12.9\%). Higher rate of Candida infection reported by (Morace et al. 1999) who recorded 31 positive samples for Candida by PCR technique out of 72 patients with hematological malignancies complaining from febrile neutropenia (43\%) and only four of them were also positive by blood culture (5.5\%). On the other hand; lower rate of Candida infection among patients with haematological malignancies recorded by Sabeeh et al. (2013) who recorded only 3 cases out of 60 leukemic patients were positive by Candida specific PCR (5\%) with only one of them was also positive by blood culture technique (1.6\%).

For evaluation of candida specific nested PCR assay against blood culture, regarded as the gold standard, showed a The specificity was $89.6 \%$ and the sensitivity $100 \%$, Positive predictive value $28.6 \%$ and negative predictive value $100 \%$,Accuracy $90 \%$ respectively, moreover the results obtained by the molecular technique correlated well with those obtained by blood culture (Kappa coeffient $0.407 \pm 0.11 \mathrm{p}<0.001$ ). These values are similar to those found in

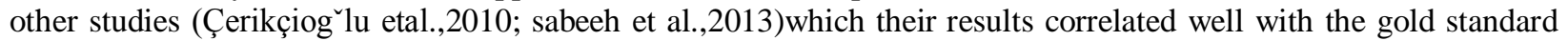
(Blood culture).

Timely rapid identification of the causative pathogens is important for adequate antimicrobial therapy especially for febrile neutropenic patients that show increased mortality with retarded diagnosis(Jordana-Lluch etal.,2014). The studied PCR techniques showed shorter turnaround time than that for automated blood culture which considered a strong additive for management of these cases . But lack of antimicrobial sensitivity reports makes culture usually necessary. 


\section{Conclusion:-}

In summary, universal broad range, Genus specific and Candida specific nested PCR assays are promising method that can be used in the rapid identification of bloodstream infections especially in immunocompromised patients with haematological malignancies, offering the possibility of identifying more positive cases that may be missed by conventional culture methods. and to rule out infection. But these techniques must be interpreted cautiously and hand-in-hand with blood culture which must associates these techniques and can't be replaced by them. Also laborious steps ( 2 sets of PCR reaction) may hinder widespread application of these techniques.

Table 1:- The relation between broad range PCR and blood culture.

\begin{tabular}{|c|c|c|c|c|c|c|c|}
\hline \multirow{2}{*}{\multicolumn{2}{|c|}{$\begin{array}{l}\text { Universal Broad range } \\
\text { PCR }\end{array}$}} & \multicolumn{2}{|c|}{ Automated blood Culture } & \multirow{3}{*}{$\begin{array}{c}\text { Total } \\
35\end{array}$} & \multirow{3}{*}{$\begin{array}{l}\text { Sensitivity } \\
\text { Specificity }\end{array}$} & \multirow[t]{2}{*}{$83.3 \%$} & \multirow{4}{*}{$\begin{array}{l}\text { Kappa } \\
\text { coeffient } \\
0.64 \pm 0.13\end{array}$} \\
\hline & & Negative & Positive & & & & \\
\hline \multirow[t]{2}{*}{-ve } & Count & 33 & 2 & & & $86.8 \%$ & \\
\hline & $\%$ of total & 66.0 & 4.0 & 70.0 & $\begin{array}{c}\text { Positive } \\
\text { predictive value }\end{array}$ & $66.7 \%$ & \\
\hline \multirow[t]{2}{*}{$+\mathrm{ve}$} & Count & 5 & 10 & 15 & $\begin{array}{c}\text { Negative } \\
\text { predictive value }\end{array}$ & $94.3 \%$ & \multirow[t]{4}{*}{$\mathbf{P}<0.001$} \\
\hline & $\%$ of total & 10.0 & 20.0 & 30.0 & \multirow[t]{3}{*}{ Accuracy } & \multirow[t]{3}{*}{$86.0 \%$} & \\
\hline \multirow[t]{2}{*}{ Total } & Count & 38 & 12 & 50 & & & \\
\hline & $\%$ of total & 76.0 & 24.0 & 100.0 & & & \\
\hline
\end{tabular}

Table 2:- The relation between Candida specific PCR and blood culture.

\begin{tabular}{|c|c|c|c|c|c|c|c|}
\hline \multirow{2}{*}{\multicolumn{2}{|c|}{$\begin{array}{c}\text { Candida specific } \\
\text { PCR }\end{array}$}} & \multicolumn{2}{|c|}{ Automated blood Culture } & \multirow{3}{*}{$\begin{array}{c}\text { Total } \\
43\end{array}$} & \multirow[t]{2}{*}{ Sensitivity } & \multirow[t]{2}{*}{100.0} & \multirow{4}{*}{$\begin{array}{c}\text { Kappa } \\
\text { coeffient } \\
0.407 \pm 0.11\end{array}$} \\
\hline & & Negative & Positive & & & & \\
\hline \multirow[t]{2}{*}{-ve } & Count & 43 & 0 & & Specificity & 89.6 & \\
\hline & $\%$ of total & 86.0 & 0.0 & 86.0 & $\begin{array}{c}\text { Positive } \\
\text { predictive value }\end{array}$ & 28.6 & \\
\hline \multirow[t]{2}{*}{$+\mathrm{ve}$} & Count & 5 & 2 & 7 & $\begin{array}{c}\text { Negative } \\
\text { predictive value }\end{array}$ & 100.0 & \multirow[t]{4}{*}{$\mathrm{P}<0.001$} \\
\hline & $\%$ of total & 10.0 & 4.0 & 14.0 & \multirow[t]{3}{*}{ Accuracy } & \multirow[t]{3}{*}{90.0} & \\
\hline \multirow[t]{2}{*}{ Total } & Count & 48 & 2 & 50 & & & \\
\hline & $\%$ of total & 96.0 & 4.0 & 100.0 & & & \\
\hline
\end{tabular}

Table 3:- The comparison between turnaround times of blood cultures versus PCR.

\begin{tabular}{|c|c|}
\hline Test & Turnarroud time \\
\hline Automated bloodculture (Negative cases) & 7 days \\
\hline Automated bloodculture (Positive cases) & $2-4$ days \\
\hline Broad range 16s PCR & 4 hours \\
\hline Genus-specific multiplex PCR & 5 hours \\
\hline Candida specific nested PCR & 8 hours \\
\hline
\end{tabular}




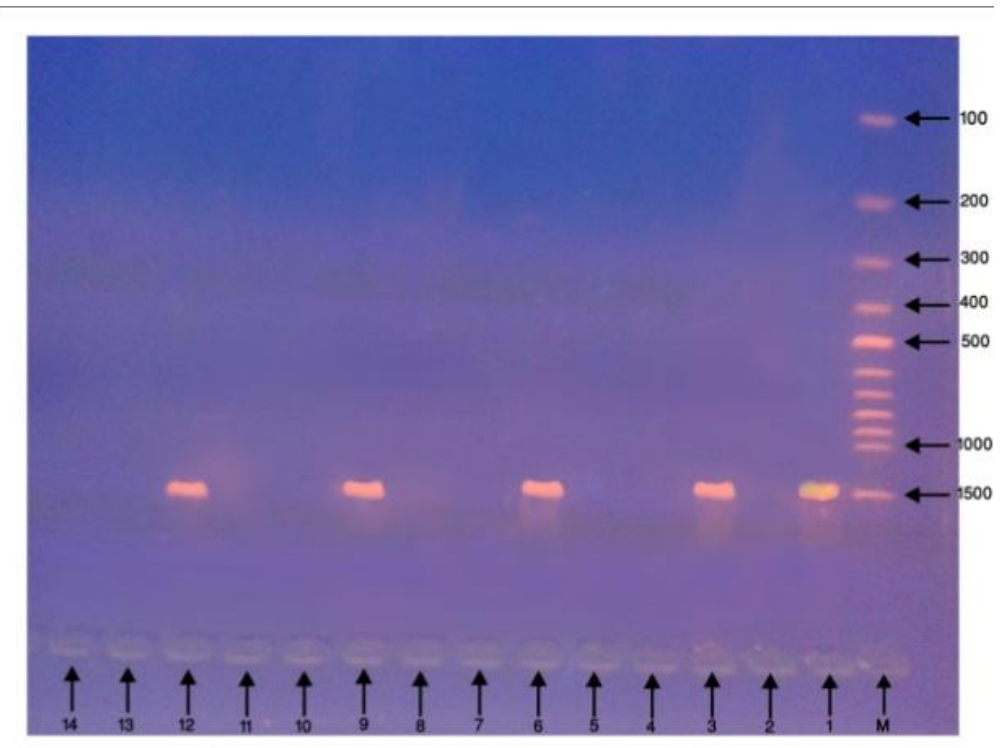

Figure 1:- Agarose gel electrophoresis indicating the presence of broad range 16S rRNA gene (1500 bp).

1. Lane M: molecular size marker.

2. Lane 1: Positive control showing positive band at $1500 \mathrm{bp}$.

3. Lane 2: Negative control.

4. Lanes 3, 6, 9, 12: correspond to the positive bacterial DNA yield.

Lanes $4,5,7,8,10,11,13 \& 14:$ correspond to the negative bacterial DNA yield

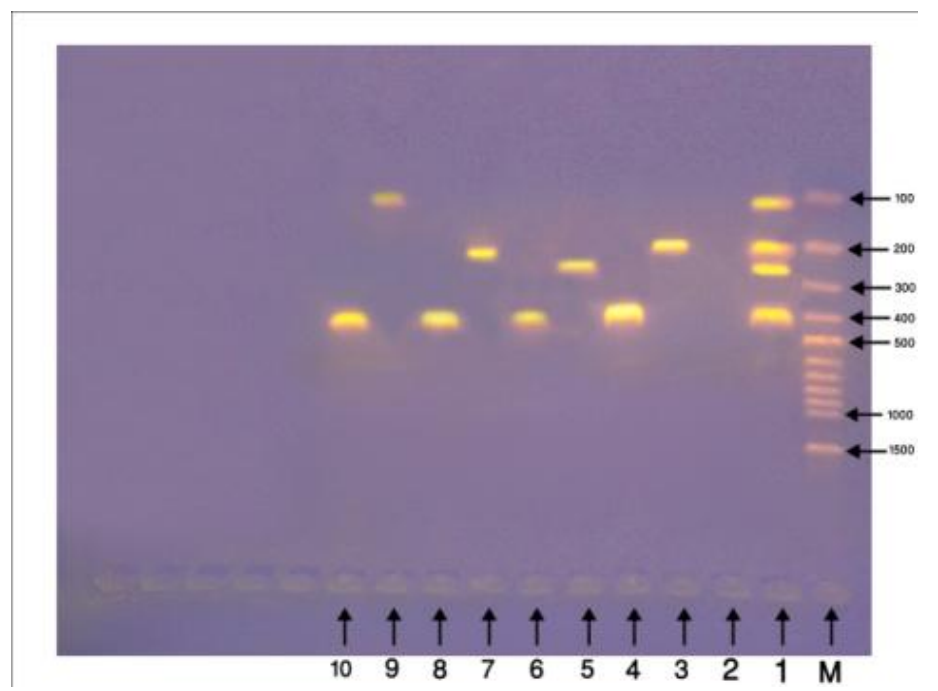

Figure 2:- Agarose gel electrophoresis following Genus- Specific multiplex PCR

Lane M: molecular size Ladder marker.

Lane 1: Positive control showing four bands at $115 \mathrm{bp}$ for enterococcus species , $215 \mathrm{bp}$ for pseudomonas species, $257 \mathrm{bp}$ for staphylococcus species and $428 \mathrm{bp}$ for enterobacteriacea .

Lane 2: Negative control.

Lanes 4, 6, 8, 10: correspond to the positive bands for enterobacteriacea.

Lanes 3, 7: correspond to the positive bands for pseudomonas species.

Lanes 5: correspond to the positive band for staphylococcus species.

Lanes 9: correspond to the positive band for Enterococcus species. 


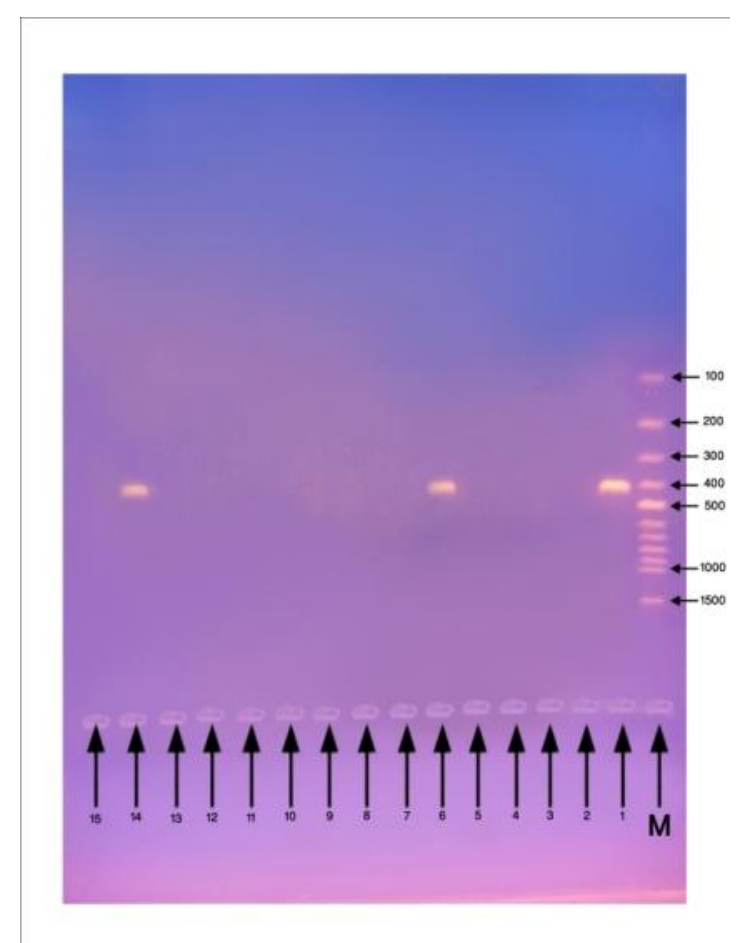

Figure 3:- Agarose gel electrophoresis indicating the presence of Candida specific gene (402 bp). Lane M: molecular size marker.

Lane 1: positive control; Lane 2: Negative control; Lanes 6 \& 14: correspond to the positive candida DNA yield;

Lanes 3, 4, 5, 7, 8, 9, 10, 11 12, 13 \& 15: correspond to the negative Candida DNA yield.

\section{References:-}

1. Arabestani, M. R., Fazzeli, H., and Esfahani ,B. N. (2014): Identification of the most common pathogenic bacteria in patients with suspected sepsis by multiplex PCR. J Infect Dev Ctries; 8(4):461-468.

2. Badiee ,P., Kordbacheh, P., Alborzi, A., Zakemia M. and Haddadi, P. (2009): Early detection of systemic candidiasis in whole blood of patients with haematologic malignancies. Jpn. J. Infect.dis., 62, 1-5.

3. Çerikçiog`lu, N., Aksu, B., Demirel ,D. T., Deniz ,U., Selva Bilgen Hülya,Özek Eren, Söyletir Güner (2010): Seminested PCR for detection and identification of Candida species directly from blood culture bottles. New Microbiologica, 33, 57-62.

4. Dark,P.M., Dean, P. and Warhurst, G. (2009): From bench-to-beside: the promise of rapid infection diagnosis during sepsis using PCR-based pathogen detection. Crit Care; 13 (4): 217.

5. De Madaria, E., Martı'nez, J., Lozano, B., Sempere, L., Benlloch, S., Such, J., Uceda, F., France's, R., Pe'rez-Mateo, M. (2005): Detection and identification of bacterial DNA in serum from patients with acute pancreatitis. Gut 54: 1293-1297.

6. De Naurois, J.,Novitzky-Basso. I., Gill, M.J., Marti, M. F, Cullen, M.H. and Roila, F. (2010): Management of febrile neutropenia: ESMO Clinical Practice Guidelines. Annals of Oncology 21 (Supplement 5): v252-v256.

7. Draz, N. I., Taha, S. E. , Abou Shady, N. M. ,Abdel Ghany, Y. S. (2013): Comparison of broad range 16S rDNA PCR to conventional blood culture for diagnosis of sepsis in the newborn. The Egyptian Journal of Medical Human Genetics (2013) 14, 403-411.

8. Jordana-Lluch, E., Giménez ,M. , Quesada, M.D. , Ausina,V. and Martró,E. (2014): Improving the Diagnosis of Bloodstream Infections: PCR Coupled with Mass Spectrometry. Hindawi Publishing Corporation BioMed Research International Volume 2014, Article ID 501214, 8 pages.

9. Gedik, H., Şimşek, F., Kantürk, A., Yildirmak ,T., Arica Deniz, A. D., Demirel, N. and Yokuş, O. (2014): Bloodstream infections in patients with hematological malignancies: which is more fatal - cancer or resistant pathogens. Therapeutics and Clinical Risk Management: 10; 743-752.

10. Gustinetti, G., Mikulska, M. (2016) : Bloodstream infections in neutropenic cancer patients: a practical update. Virulence. 2016 Apr 2;7(3):280-97. 
11. Isaacman, D.J., Karasic, R.B., Reynolds, E.A., Kost, S.I. (1996) Effect of number of blood cultures and volume of blood on detection of bacteremia in children. J Pediatr 128 Suppl 2: 190-195.

12. Jaeger ,E. E. M., Carroll ,N. M., Choudhury ,S., Dunlop ,A. A. S.,Towler, H. M. A., Matheson M. M., Adamson, P., Okhravi ,N.S,And Lightman, S.(2000): Rapid Detection and Identification of Candida, Aspergillus, and Fusarium Species in Ocular Samples Using Nested PCR. Journal Of Clinical Microbiology,Aug. 2000, p. 2902-2908 Vol. 38, No. 8.

13. Jordan, J.A. and Durso, M.B. (2005): Real-Time Polymerase Chain Reaction for Detecting Bacterial DNA Directly from Blood of Neonates Being Evaluated for Sepsis. Journal of Molecular Diagnostics, Vol. 7, No. 5, pp 575-581.

14. Kempf, V.A., Trebesius, K., Autenrieth, I.B. (2000) Fluorescent in situ hybridization allows rapid identification of microorganisms in blood cultures. J Clin Microbiol 38: 830-838.

15. Kirn, T.J. and Weinstein, M.P. (2013): Update on blood cultures: how to obtain, process, report, and interpret. Clinical Microbiology and Infection: the official publication of the European Society of Clinical Microbiology and Infectious Diseases 19, 513-520.

16. Lakshmaiah, K.C., Abhayakumar, S.M., Govindbabu, K., Shetty, R., Sinha, M. and Jayashree, R.S. (2015) : Febrile Neutropenia in Hematological Malignancies: Clinical and Microbiological Profile and Outcome in High Risk Patients.J Lab Physicians. 2015 Jul-Dec; 7(2): 116-120.

17. Lamoth, F., Jaton, K., Prodhom, G., Senn, L., Bille, J., Calandra, T. and Marchetti, O. (2010): Multiplex Blood PCR in Combination with Blood Cultures for Improvement of Microbiological Documentation of Infection in Febrile Neutropenia. Journal Of Clinical Microbiology, Vol. 48, No. 10 pp. 3510-3516.

18. Lau,A., Halliday, C., Chen, S.C.A., Playford, E. G., Stanley, K. and Sorrell, T.C. (2009): Comparison of Whole Blood, Serum, and Plasma for Early Detection of Candidemia by Multiplex-Tandem PCR. Journal Of Clinical Microbiology, Vol. 48, No. 3, p. 811-816.

19. Liesenfeld, O., Lehman, L., Hunfeld, K.P. and Kost, G. (2014): Molecular diagnosis of sepsis: new aspects and recent developments. European Journal of Microbiology and Immunology 4 (2014) 1, pp. 1-25.

20. Mancini,N.,Silvia,C., Nadia, G., Paola, C., Roberto, B., and Massimo, C. (2010): The Era of Molecular and Other Non-Culture-Based Methods in Diagnosis of Sepsis. Clinical Microbiology Reviews, Vol. 23, No. 1 pp. 235-251

21. Metwally, L., Hogg, G., Coyle, P. V., Hay, R. J., Hedderwick, S.,McCloskey, B., O’Neill, H. J., Ong, G. M., Thompson, G., Webb, C. H. and McMullan ,R. (2007): Rapid differentiation between fluconazolesensitive and -resistant species of Candida directly from positive blood-culture bottles by real-time PCR. Journal of Medical Microbiology (2007), 56, 964-970.

22. Mitsuda,Y., Takeshima, Y., Mori, T., Yanai, T., Hayakawa, A., And Matsuo, M. (2011): Utility of Multiplex PCR in Detecting the Causative Pathogens for Pediatric Febrile Neutropenia. Kobe J. Med. Sci., Vol. 57, No. 2, pp. E32-E37.

23. Morace, G., Pagano, L., Sanguinetti, M., Posteraro, B., Mele, L. and Equitani, F. (1999): PCR-restriction enzyme analysis for detection of Candida DNA in blood from febrile patients with hematological malignancies. J Clin Microbiol.; 37(6): 1871-5.

24. Muhl,H., Kochem, A.J., Disque, C. and Sakka, S.G. (2010): Activity and DNA contamination of commercial polymerase chain reaction reagents for the universal $16 \mathrm{~S}$ rDNA real-time polymerase chain reaction detection of bacterial pathogens in blood. Diagn Microbiol Infect Dis. 66(1):41-9.

25. Murray, P.R., Masur, H. (2012): Current approaches to the diagnosis of bacterial and fungal bloodstream infections in the intensive care unit. Crit Care Med 40 Suppl 12: 3277-3282.

26. Nguyen, H., Mark, C.W., Ryan, K.S., Martin, A.S., Binghua, H., Ellen, G.P., Ryan, M.S., Shaoji, C., Dimitra, M., Aniket, V., Fernanda, P.S., Steven, B.K., and Cornelius, J.C. (2012): Performance of Candida Real-time Polymerase Chain Reaction, b-D-Glucan Assay, and Blood Cultures in the Diagnosis of Invasive Candidiasis. Clinical Infectious Diseases; 54 (9):1240-8.

27. Nørgaard, M. (2012): Risk of Infections in Adult Patients with Haematological Malignancies. The Open Infectious Diseases Journal, Volume 6 (Suppl 1: M4) 46-51.

28. Phillips, R.S., Sung, L., Amman, R. A, Riley, R.D, Castagnola, E. et al.,(2016): Predicting microbiologically defined infection in febrile neutropenic episodes in children: global individual participant data multivariable meta-analysis .British Journal of cancer 114, p $623-630$.

29. Pierrakos, C., Vincent, J.L. (2010): Sepsis biomarkers: a review. Crit Care 14: R15.

30. Rodriguez-Creixems, M., Alcala, L., Munoz, P., Cercenado, E., Vicente, T., Bouza, E. (2008): Bloodstream infections: evolution and trends in the microbiology workload, incidence, and etiology, 1985-2006. Medicine (Baltimore) 87 Suppl 4: 234-249. 
31. Rothman, R.E., Majmudar, M.D., Kelen, G.D., Madico, G., Gaydos, C.A. and Walker, T. (2002): Detection of bacteremia in emergency department patients at risk for infective endocarditis using universal $16 \mathrm{~S}$ rRNA primers in a decontaminated polymerase chain reaction assay. J Infect Dis.; 186: 1677-81.

32. Sabeeh, S., Al-Attraqhchi, A.A.F., and Al-Aswad, E. (2013): PCR in Comparison with Culture Methods for The Diagnosis of Candida albicans Responsible for Candidemia in Leukemic Patients. Diyala Journal of Medicine; Vol. 5, Issue 2.

33. Teranishi, H. and Ouchi, K. (2014): Detection of bacteria, fungi, and viruses by a real-time PCR assay using universal primers and probes from blood in patients with febrile neutropenia. Kawasaki Medical Journal, 40 (1): $1-14$.

34. Von Lilienfeld-Toal, M., Lehmann, L. E., Raadts, A. D., Hahn-Ast, C., Orlopp, K. S., Marklein, G., Purr, I., Cook, G., Hoeft, A., Glasmacher, A. and Stüber, F. (2009): Utility of a Commercially Available Multiplex Real-Time PCR AssayTo Detect Bacterial and Fungal Pathogens in Febrile Neutropenia. Journal Of Clinical Microbiology, Vol. 47, No. 8. pp. 2405-2410.

35. Wellinghausen, N., Kochem, A.J., Disqué C., Muhl, H., Gebert, S., Winter, J., Matten, J. and Sakka, S.G. (2009): Diagnosis of bacteremia in whole-blood samples by use of a commercial universal 16S rRNA genebased PCR and sequence analysis. J Clin Microbiol 47: 2759-2765.

36. Woese, C.R. (1987): Bacterial evolution. Microbiol Rev 51 Suppl 2: 221-271. 